\title{
Burnout and compassion fatigue: prevalence and associations among Israeli burn clinicians
}

\author{
This article was published in the following Dove Press journal: \\ Neuropsychiatric Disease and Treatment \\ 15 June 2017 \\ Number of times this article has been viewed
}

\author{
Josef Haik ${ }^{1-3}$ \\ Stav Brown ${ }^{1,2}$ \\ Alon Liran' \\ Denis Visentin ${ }^{4}$ \\ Amit Sokolov ${ }^{2}$ \\ Isaac Zilinsky ${ }^{1,2}$ \\ Rachel Kornhaber ${ }^{1,4}$ \\ 'Department of Plastic and \\ Reconstruction Surgery, The National \\ Burns Center, Sheba Medical Center, \\ Tel Hashomer, ${ }^{2}$ Sackler Faculty of \\ Medicine, Tel Aviv University, Tel Aviv, \\ ${ }^{3}$ Talpiot Medical Leadership Program, \\ Sheba Medical Center, Tel Hashomer. \\ Israel; ${ }^{4} \mathrm{~S} c h o o l$ of Health Sciences, \\ Faculty of Health, University of \\ Tasmania, Sydney, NSW, Australia
}

Correspondence: Josef Haik

Department of Plastic and Reconstruction Surgery, The National Burns Center, Sheba Medical Center, Tel Hashomer, Emek HaEla St I, Ramat Gan, Israel Email josef.haik@sheba.health.gov.il

\begin{abstract}
Acute health care environments can be stressful settings with clinicians experiencing deleterious effects of burnout and compassion fatigue affecting their mental health. Subsequently, the quality of patient care and outcomes may be threatened if clinicians experience burnout or compassion fatigue. Therefore, the aim of this descriptive, cross-sectional study was to evaluate the prevalence of burnout and compassion fatigue among burn clinicians in Israel. Fifty-five clinicians from Burns, Plastics and Reconstruction Surgery and Intensive Care completed four validated surveys to assess burnout (Maslach Burnout Inventory), depression (PRIME-MD), healthrelated quality of life (SF-8), and compassion fatigue (Professional Quality of Life version 5). Burn clinicians were compared with Plastics and Reconstruction Surgery and Intensive Care clinicians. This study identified a high prevalence of burnout (38.2\%) among Intensive Care, Plastics and Reconstruction and Burns clinicians, with Burns clinicians having a greatly increased prevalence of burnout compared to Intensive Care clinicians ( $\mathrm{OR}=24.3, P=0.017)$. Additional factors contributing to compassion fatigue were those without children $(P=0.016)$, divorced ( $P=0.035)$, of a younger age $(P=0.019)$, and a registered nurse $(P=0.05)$. Burnout increased clinicians' risk of adverse professional and personal outcomes and correlated with less free time $(P<0.001)$, increased risk of experiencing work-home disputes $(P=0.05)$, increased depression $(P=0.001)$ and decreased career satisfaction $(P=0.01)$. Burnout was also associated with higher physical $($ mean difference $=3.8, P<0.001)$ and lower mental $($ mean difference $=-3.5, P<0.001)$ Quality of Life scores. Caring for burn survivors can lead to burnout, compassion fatigue, and vicarious trauma. Identifying strategies to abate these issues is essential to ensure improved clinicial environments and patient outcomes.
\end{abstract}

Keywords: burnout, compassion fatigue, professional quality of life scale, resilience, burns, health personnel, emotional intelligence, psychological stress

\section{Introduction}

Occupational burnout remains a global phenomenon related to the quality of the working environment, workload, relationships, and conflict. ${ }^{1}$ Subsequently, a growing body of literature is emerging concerning clinicians' quality of life (QoL) encompassing compassion fatigue and burnout in the field of trauma. ${ }^{2}$ Research suggests that clinicians working in the health care professions are at greater risk of adverse psychological implications resulting from direct patient interactions. ${ }^{3}$ Repeated exposure to traumatic injuries has the propensity to increase the risk of burnout, compassion fatigue, and secondary traumatic stress in health care professionals. ${ }^{4}$ Consequently, the concept of vicarious trauma has gained interest in professions related to the domain of trauma. ${ }^{5}$ Within the health care setting, burnout in clinicians can be defined as a psychological syndrome of emotional exhaustion, patient depersonalization, negative views of patients, and diminished feelings of both personal and work accomplishments. ${ }^{6}$ 
Subsequently, when emotional resources deplete, individuals are left feeling that they no longer have the capacity to give of themselves ${ }^{6}$ with significant effects on health care system cohesion.

Providing care and social support to people experiencing traumatic events may be both rewarding and at the same time stressful. ${ }^{7}$ Such stress from providing care has been coined as "burden of care". ${ }^{7}$ Continual exposure to demanding, stressful, and traumatic encounters can result in a cost of caring, which is known as "compassion fatigue". ${ }^{8}$ Subsequently, health care professionals who experience continual contact with trauma patients are at risk of compassion fatigue. ${ }^{9}$ Given that health professionals play a key role in the patients' care trajectory, it is critical to understand both the occupational and environmental impact on clinicians' psychological health and job satisfaction as this will influence future retention and recruitment to areas involving high trauma. While the literature concerning burnout and compassion fatigue in health care is well documented, these have not been extensively studied in the domain of burn injury. Therefore, the aim of this descriptive, cross-sectional study was to evaluate the prevalence of burnout and compassion fatigue among burn clinicians in Israel.

\section{Methods}

\section{Study design and recruitment}

The research was conducted in accordance with the Declaration of Helsinki. Ethical approval was granted by the Hospital Research Ethics Committee of Sheba Medical Center in Israel, and informed consent was obtained from the individuals prior to commencement of the study. Furthermore, it is reported that the domain of traumatic stress has enhanced knowledge concerning minimal risk, in particular distress, which suggests emotional distress is infrequent in well-conducted studies concerning trauma. ${ }^{10}$ Subsequently, all participants were informed that social support was available if they felt distressed or anxious as a result of participation. Participants were provided with the study's aims and objectives and informed that participation was anonymous and on a voluntary basis. The study population consisted of 60 clinicians from Burns, Intensive Care, and Plastics and Reconstruction Surgery at the Sheba Medical Center, Tel Hashomer, Israel. All 60 clinicians consented to participate, a total of 57 (95\%) returned the questionnaire of which two incomplete questionnaires were excluded, and hence 55 questionnaires were analyzed.

\section{Questionnaire}

Four survey tools were used to assess various domains: burnout was measured using the Maslach Burnout Inventory
(MBI), depression was assessed using the Primary Care evaluation of Mental Disorders, QoL was assessed using the SF-8 health survey, and compassion fatigue was assessed using the Professional Quality of Life (ProQOL) measure. Additional parameters, including demographics, practice characteristics, career satisfaction, and work-family-home conflicts, were collected via questions adapted from Shanafelt et al. ${ }^{11}$ The questionnaires were provided at one time point to the participants in a paper-based form and the anonymity of participants was maintained.

The MBI, a validated measure for diagnosis of burnout, ${ }^{12}$ is a 22-item questionnaire that evaluates three subscales of burnout: emotional exhaustion (EE), depersonalization (DP), and personal accomplishment (PA). Each question is graded on a 7-point Likert scale to calculate scores for each of the three subscales. Scores for each subscale were assessed for critical levels to determine proportion of subjects at risk according to the Maslach scoring guidelines. ${ }^{12}$ Cut-off points for high levels for EE and DP were scores $>27$ and $>10$, respectively, and the cut-off for low levels for PA was scores $<33$. Since low scores for PA are considered less important in detecting burnout symptoms, ${ }^{13}$ burnout was defined as a high score on the DP and/or EE subscales (EE score $>27$ and/or DP score $>10$, in accordance with Shanafelt et al. ${ }^{11}$ Depression symptomology was identified using the 2-item Primary Care Evaluation of Mental Disorders (PRIME MD), a standardized depressionscreening tool. ${ }^{14}$

Mental and physical QoL were examined using the SF-8 Health Survey, a validated questionnaire assessing healthrelated QoL ${ }^{15}$ consisting of eight items encompassing general and mental health, physical and social functioning, and role limitations due to physical and emotional health problems, bodily pain, energy, and fatigue. ${ }^{15}$

Additional standardized questions were developed from previous surveys targeted to medical professionals in order to evaluate personal and professional characteristics such as career satisfaction, work-family-home stressors, and demographic factors that may be possible risk factors for developing burnout symptoms and compassion fatigue in this cohort. ${ }^{16,17}$

Compassion fatigue was evaluated by the ProQOL version 5, a validated, 30-item questionnaire (ProQOL5). ${ }^{18}$ The ProQOL5 includes three subscales for the components of compassion fatigue: compassion satisfaction, burnout, and secondary traumatic stress. The score range for each category is 5-50, with low compassion satisfaction, high burnout, and high secondary traumatic stress scores increasing the likelihood 
for compassion fatigue. ${ }^{19}$ Scores were stratified to low (22 or lower), average (23-41), and high (42 or higher).

\section{Statistical analysis}

Statistical analysis was performed using SPSS Version 17.0 (SPSS Inc., Chicago, IL, USA). Incomplete questionnaires were excluded from the analysis. Associations between burnout and risk factors/adverse outcomes were compared by two methods. First, univariate analysis was performed using chi-square tests for categorical variables and MannWhitney $U$-tests for continuous variables, with a nominal decision level of $P<0.05$ modified by Bonferroni correction for multiple comparisons. Multivariate analysis was then performed using logistic regression with forward selection, using a decision level of $P<0.05$. The variables used in the model for burnout were age, role, department, gender, relationship status, child-rearing status, years in practice, weekly work hours, and weekly night shifts. Multivariate analysis using linear regression was conducted to assess the influence of these variables on the three ProQOL subscales (compassion satisfaction, burnout, and secondary traumatic stress), with a decision level of $P<0.05$. Finally, associations between burnout, personal, and professional characteristics were compared using the same univariate methods as in the first analysis. The variables used in the model for burnout impacts were work-home-family conflicts, depression, mental and physical QoL, impairment, and career satisfaction.

\section{Results}

Demographic and professional characteristics of the study participants are summarized in Table 1. Of the respondents,

Table I Demographic and professional characteristics

\begin{tabular}{|c|c|c|}
\hline Characteristic & Category & $\begin{array}{l}\mathbf{N}(\%) \text { or } \\
\text { mean (SD) }\end{array}$ \\
\hline Personal characteristics & No of participants & 55 (100\%) \\
\hline Gender & Female & 32 (58.2\%) \\
\hline \multirow[t]{3}{*}{ Relationship status } & Single & 12 (2I.8\%) \\
\hline & Married & $37(67.3 \%)$ \\
\hline & Divorced & $6(10.9 \%)$ \\
\hline Children & Yes & $37(67.3 \%)$ \\
\hline \multicolumn{3}{|c|}{ Professional characteristics } \\
\hline \multirow[t]{3}{*}{ Department } & Burn unit & $19(34.6 \%)$ \\
\hline & Plastics & $16(29.0 \%)$ \\
\hline & $\mathrm{ICU}$ & $20(36.4 \%)$ \\
\hline Experience & Years in practice & $12.25(9.44 \%)$ \\
\hline \multirow[t]{3}{*}{ Role } & Attending & $13(23.6 \%)$ \\
\hline & Resident & I4 (25.4\%) \\
\hline & RN & $28(51.0 \%)$ \\
\hline Work hours & Weekly work hours & $49.5(15.3)$ \\
\hline Night shifts & Weekly night shifts & $1.6(1.2)$ \\
\hline
\end{tabular}

Abbreviations: RN, registered nurse; ICU, Intensive Care Unit.
34.6\% were from Burns, 29\% from Plastics and Reconstruction, and $36.4 \%$ from the Intensive Care Unit (ICU). The mean age of participants was 40.0 years of whom $58.1 \%$ were female. The mean clinical practice experience was 12.2 years, working an average of 49.5 hours per week, with an average of 1.6 night shifts per week. The marital status of the participants revealed that $21.8 \%$ were single, $10.9 \%$ were divorced, $67.3 \%$ were married, while $67.3 \%$ had children.

Table 2 presents frequency and percentages of participants demonstrating burnout (assessed by MBI) and compassion satisfaction (assessed by ProQOL5) including the three

Table $2 \mathrm{MBI}$ burnout, ${ }^{\mathrm{a}}$ compassion fatigue, and other measured characteristics

\begin{tabular}{|c|c|c|}
\hline Characteristic & Category & $\begin{array}{l}\mathrm{N}(\%) \text { or } \\
\text { mean (SD) }\end{array}$ \\
\hline \multicolumn{3}{|l|}{ MBI } \\
\hline MBI burnout & Yes & 21 (38.2\%) \\
\hline \multirow[t]{2}{*}{ Emotional exhaustion } & Score & $24.3(9.3)$ \\
\hline & $\mathrm{High}^{\mathrm{b}}$ & $19(34.5 \%)$ \\
\hline \multirow[t]{2}{*}{ Depersonalization } & Score & $9.3(2.4)$ \\
\hline & $\mathrm{High}^{\mathrm{b}}$ & $15(27.3 \%)$ \\
\hline \multirow[t]{2}{*}{ Personal achievement } & Score & $34.9(3.4)$ \\
\hline & $\mathrm{High}^{\mathrm{b}}$ & $16(29.0 \%)$ \\
\hline \multicolumn{3}{|l|}{ ProQOL5 - compassion fatigue } \\
\hline \multirow[t]{3}{*}{ Compassion satisfaction } & Score & $33.1(8.4)$ \\
\hline & Low & $2(3.7 \%)$ \\
\hline & High & $14(25.5 \%)$ \\
\hline \multirow[t]{3}{*}{ ProQOL5 burnout } & Score & $36.3(7.2)$ \\
\hline & Low & $5(9.1 \%)$ \\
\hline & High & $15(27.3 \%)$ \\
\hline \multirow[t]{3}{*}{ Secondary traumatic stress } & Score & $36.4(5.9)$ \\
\hline & Low & $\mathrm{I}(\mathrm{I} .8 \%)$ \\
\hline & High & $13(23.6 \%)$ \\
\hline \multicolumn{3}{|c|}{ Depression, QoL, impairment, and career satisfaction } \\
\hline \multirow[t]{2}{*}{ Depression } & Yes & $16(29.1 \%)$ \\
\hline & No & 39 (70.9\%) \\
\hline \multirow[t]{4}{*}{ QoL } & Mental score & $47.0(3.1)$ \\
\hline & Poor mental score & 14 (25.5\%) \\
\hline & Physical score & $46.3(3.2)$ \\
\hline & Poor physical score & $16(29.0 \%)$ \\
\hline Work-home conflicts & Yes & 35 (63.7\%) \\
\hline Free time & Yes & $38(69.0 \%)$ \\
\hline Time for sports & Yes & $37(67.3 \%)$ \\
\hline $\begin{array}{l}\text { Would you become a } \\
\text { medical caregiver again? }\end{array}$ & Yes & $46(83.6 \%)$ \\
\hline $\begin{array}{l}\text { Would you choose a } \\
\text { surgical environment again? }\end{array}$ & Yes & $33(60.0 \%)$ \\
\hline \multirow[t]{2}{*}{ Sleep deprivation } & $\begin{array}{l}\text { Hours of sleep } \\
\text { per night }\end{array}$ & $5.73(0.87)$ \\
\hline & $\begin{array}{l}\text { Sleep deprivation } \\
(\text { hour }<6 \text { ) }\end{array}$ & $24(43.6 \%)$ \\
\hline
\end{tabular}

Notes: aMBI burnout where EE score $>27$ and/or DP score $>10$. ${ }^{\text {CCut-off levels }}$ $\mathrm{EE}>27, \mathrm{DP}>10, \mathrm{PA}<33$

Abbreviations: $\mathrm{EE}$, emotional exhaustion; DP, depersonalization; MBI, Maslach Burnout Inventory; PA, personal accomplishment; ProQOL5, Professional Quality of Life version 5; QoL, Quality of Life. 
sub-classifications for each measure, and other measures of depression, QoL, and career satisfaction. MBI results for burnout show $38.2 \%$ of study participants experienced burnout, with 29\% having low scores for PA, 27.3\% exhibiting high DP, and $34.5 \%$ experiencing high EE. The mean values for all three measures were within the normal range but close to the clinically critical value in each case $(\mathrm{EE}=24.3$ [6.0], DP =9.3 [2.4], PA =34.9 [3.4]). Burn clinicians demonstrated a higher prevalence of burnout (58\%). ProQOL5 Compassion Fatigue results show only $3.7 \%$ of study participants experienced low compassion satisfaction, with $27.3 \%$ having high scores for burnout, and 23.6\% exhibiting high secondary traumatic stress. Depression results show 29.1\% of respondents exhibiting depression. The mean scores for the mental and physical QoL components were 47.0 and 46.3, respectively, with $25.5 \%$ of participants demonstrating a poor mental QoL and $29.0 \%$ of participants demonstrating a poor physical QoL. Respondents reported an average of 5.7 hours of sleep per night, with $43.6 \%$ experiencing $<6$ hours of sleep per night.

Table 3 presents risk factors (personal and professional) associated with burnout (as assessed by MBI) from a univariate analysis, with correction for multiple comparisons used in determining $P$-values, and the same risk factors retained in multivariate logistic regression. Characteristics with a high associated overall risk for burnout in the univariate analysis included not having children $(P<0.001)$, fewer years of practice $(P<0.001)$, and younger age $(P<0.001)$. Odds ratios were determined for risk factors in the multivariate analysis, demonstrating an increased risk of burnout for burns clinicians compared to ICU clinicians $(\mathrm{OR}=24.3 ; P=0.017)$. Protective factors for burnout were having children $(\mathrm{OR}=0.05 ; P=0.019)$ and older age (OR $=0.79 ; P=0.019)$. Other factors such as role, gender, relationship status, years in practice, weekly work hours, and weekly night shifts were not identified as having a significant association with burnout.

Table 4 presents the risk factors associated with ProQOL5 Compassion Fatigue scores for burnout, compassion, and secondary traumatic stress obtained from a multivariate linear regression. Working as a burns clinician compared to ICU was associated with significantly higher burnout score (difference $=8.1 ; P<0.001$ ) and lower compassion satisfaction score (difference $=-8 ; P=0.02$ ), indicating increased compassion fatigue, and higher secondary traumatic stress score (difference $=4.5 ; P=0.02$ ), indicating higher secondary traumatic stress. Additional significant factors associated with higher secondary traumatic stress score were working as a registered nurse (compared to Resident)
Table 3 Univariate and multivariate analyses of risk factors for $\mathrm{MBI}$ burnout ${ }^{\mathrm{a}}$

\begin{tabular}{|c|c|c|c|c|}
\hline Factor & $\mathbf{N}$ & $\begin{array}{l}\% \text { MBI } \\
\text { burnout or } \\
\text { mean } \pm \text { SD } \\
(n=2 I)\end{array}$ & $\begin{array}{l}\% \text { non-MBI } \\
\text { burnout or } \\
\text { mean } \pm \text { SD } \\
(n=34)\end{array}$ & $P$-value \\
\hline \multicolumn{5}{|l|}{ Univariate analysis } \\
\hline Role & & & & 0.14 \\
\hline $\mathrm{RN}$ & 28 & 43 & 57 & \\
\hline Attending & 13 & 15 & 85 & \\
\hline Resident & 14 & 50 & 50 & \\
\hline Department & & & & 0.09 \\
\hline ICU & 20 & 30 & 70 & \\
\hline Plastics & 16 & 25 & 75 & \\
\hline Burns & 19 & 58 & 42 & \\
\hline Gender & & & & 0.12 \\
\hline Male & 23 & 26 & 74 & \\
\hline Female & 32 & 47 & 53 & \\
\hline Relationship status & & & & 0.054 \\
\hline Single & 12 & 67 & 33 & \\
\hline Married & 37 & 32 & 68 & \\
\hline Divorced & 6 & 17 & 83 & \\
\hline Children & & & & $<0.00 \mathrm{I}^{\mathrm{b}}$ \\
\hline Yes & 37 & 19 & 81 & \\
\hline No & 18 & 78 & 22 & \\
\hline Years in practice & 55 & $6 \pm 4.9$ & $16.1 \pm 9.7$ & $<0.00 \mathrm{I}^{\mathrm{b}}$ \\
\hline Age & 55 & $34.2 \pm 6.1$ & $43.6 \pm 7.5$ & $<0.00 \mathrm{I}^{\mathrm{b}}$ \\
\hline Weekly work hours & 55 & $49.8 \pm 14.6$ & $49.3 \pm 15.9$ & 0.71 \\
\hline Weekly night shifts & 55 & $1.5 \pm 1.3$ & $1.7 \pm 1.2$ & 0.58 \\
\hline \multicolumn{2}{|c|}{ Multivariate analysis } & \multicolumn{2}{|c|}{ OR $(95 \% \mathrm{CI})$} & $P$-value \\
\hline \multicolumn{2}{|c|}{ Plastics (compared to ICU) } & \multicolumn{2}{|c|}{$0.29(0.03,3.1)$} & 0.31 \\
\hline \multirow{2}{*}{\multicolumn{2}{|c|}{ Burns (compared to ICU) }} & \multicolumn{2}{|c|}{$24.3(1.8,330)$} & $0.017^{\mathrm{b}}$ \\
\hline & & \multicolumn{2}{|c|}{$0.05(0.004,0.6 \mathrm{I})$} & $0.019^{b}$ \\
\hline \multicolumn{2}{|l|}{ Age } & \multicolumn{2}{|c|}{$0.79(0.65,0.96)$} & $0.019^{b}$ \\
\hline \multicolumn{5}{|c|}{$\begin{array}{l}\text { Notes: aMBI Burnout where EE score }>27 \text { and/or DP score }>10 \text {. bStatistically } \\
\text { significant after correction for multiple comparisons. }\end{array}$} \\
\hline \multicolumn{5}{|c|}{ Abbreviations: $\mathrm{EE}$, emotional exhaustion; DP, depersonalization; ICU, Intensive } \\
\hline
\end{tabular}

(difference $=4.2 ; P=0.05$ ) and being divorced (compared to single) (difference $=6.5 ; P=0.035$ ).

Table 5 presents associations between burnout (as measured by MBI) and QoL and Career Satisfaction measures. Burnout was shown to be associated with the risk of adverse

Table 4 Significant associations of factors on ProQoL5 scores for burnout, compassion, and secondary traumatic stress (multivariate analysis)

\begin{tabular}{|c|c|c|}
\hline Factor & Effect $(95 \% \mathrm{Cl})$ & $P$-value \\
\hline \multicolumn{3}{|l|}{ ProQoL5 burnout score } \\
\hline Burns (compared to ICU) & $8.1(4.1,12.1)$ & $<0.001$ \\
\hline \multicolumn{3}{|l|}{ ProQoL5 Compassion score } \\
\hline Burns (compared to ICU) & $-8.0(-13.1,-2.9)$ & 0.002 \\
\hline Having children & $10.5(4.8,16.1)$ & $<0.001$ \\
\hline \multicolumn{3}{|c|}{ ProQoL5 secondary traumatic stress score } \\
\hline RN (compared to Resident) & $4.2(0.009,8.4)$ & 0.05 \\
\hline Burns (compared to ICU) & $4.5(0.66,8.4)$ & 0.02 \\
\hline Divorced (compared to single) & $6.5(0.47,12.4)$ & 0.035 \\
\hline Having children & $-5.3(-9.6,-1)$ & 0.016 \\
\hline
\end{tabular}

Abbreviations: ICU, Intensive Care Unit; ProQOL5, Professional Quality of Life version 5 ; RN, registered nurse. 
Table 5 Burnout associations on quality of life and career satisfaction measures (univariate analysis)

\begin{tabular}{|c|c|c|c|c|}
\hline Factor & $\mathbf{N}$ & $\begin{array}{l}\text { Burnout } \\
(n=2 I), \% \text { or } \\
\text { mean } \pm \text { SD }\end{array}$ & $\begin{array}{l}\text { Non-burnout } \\
(n=34), \% \text { or } \\
\text { mean } \pm \text { SD }\end{array}$ & P-value \\
\hline Free time & 38 & $16 \%$ & $84 \%$ & $<0.00 I^{\mathrm{a}}$ \\
\hline Time for sport & 18 & $39 \%$ & $61 \%$ & 0.58 \\
\hline Work-home conflicts & 35 & $29 \%$ & $71 \%$ & 0.05 \\
\hline Depression & 16 & $75 \%$ & $25 \%$ & $0.00 \mathrm{I}^{\mathrm{a}}$ \\
\hline $\begin{array}{l}\text { Would you become a } \\
\text { medical caregiver again? }\end{array}$ & 46 & $30 \%$ & $70 \%$ & 0.011 \\
\hline $\begin{array}{l}\text { Would you choose a } \\
\text { surgical environment again? }\end{array}$ & 33 & $24 \%$ & $76 \%$ & 0.01 \\
\hline Daily hours of sleep & & $5.6 \pm 0.7$ & $5.8 \pm 1$ & 0.37 \\
\hline Physical score & & $48.6 \pm 2.3$ & $44.8 \pm 2.7$ & $<0.00 I^{\mathrm{a}}$ \\
\hline Mental score & & $44.8 \pm 2.1$ & $48.3 \pm 2.9$ & $<0.001^{a}$ \\
\hline
\end{tabular}

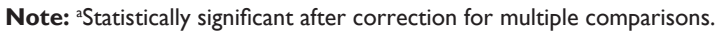

professional and personal outcomes, with statistically significant relationships being less free time $(P<0.001)$ and increased depression $(P=0.001)$. Burnout was also associated with higher QoL mental health problem score $(P<0.001)$ and lower QoL mental problem health score $(P<0.001)$. Additional factors did not show significance after correction for multiple comparisons: increased work-home conflicts $(P=0.05)$ and lower career satisfaction (medical career, $P=0.01$, surgical environment $P=0.01$ ).

\section{Discussion}

Our study aimed to evaluate the prevalence of burnout and compassion fatigue among burn clinicians in Israel using four validated tools and also evaluate risk factors. The burns environment speaks to a combination of constant exposure to traumatic events and acute care challenges alongside long-term complex wound care, requiring life-long rehabilitation. Subsequently, this may influence the prevalence of burnout among burn clinicians. Furthermore, other studies suggest that clinicians, who care for chronically or critically ill patients, could be at risk of burnout compared to other disciplines that encompass curable conditions with more positive outcomes. ${ }^{20}$

There have been several studies that have investigated burnout and compassion fatigue in the domain of burns trauma. ${ }^{2,21-30}$ Our findings demonstrate a high prevalence of burnout (38.2\%) among clinicians from burns, ICU, and plastics and reconstruction. The increased burnout prevalence among burn clinicians was high at $58 \%$, with these clinicians having a greatly increased prevalence of burnout compared to ICU clinicians identified in the multivariate analysis $(\mathrm{OR}=24.3, P=0.017)$. ICU burnout rates were also higher than plastics and reconstruction rates, although this difference was not identified as statistically significant in this study.

Burn care clinicians demonstrated higher scores for both EE and DP but lower scores for PA than overall. Sahraian et a ${ }^{26}$ who also evaluated burnout rates in nursing staff across disciplines including burns, psychiatry, surgery, and internal medicine found similar proportions of burnout overall (25\%) with increased rates for burns nurses (28.9\%). Burns nurses had a significantly higher PA score (36.2\%) but had lower scores for DP (4.4\%) and higher EE scores (26.1\%) compared to the overall results. ${ }^{26}$ These results are generally consistent with our study; however, we found a greatly increased risk for burns clinicians compared to ICU, of whom the majority were nurses, and higher values for DP in our study.

Multivariate analysis revealed that increased age (OR $=0.05, P=0.019)$ was an independent protective factor for burnout and having children ( $\mathrm{OR}=0.79, P=0.019$ ) was also protective but with a lesser effect. This concurs with Shanafelt et $\mathrm{al}^{11}$ who found that having children and increased age were associated with a lower risk of burnout. Having children seems to place clinicians at a decreased risk for both burnout and compassion fatigue as children may serve as a source of emotional support and distraction from workrelated stressors. The multivariate analysis did not identify years in practice as a significant factor, whereas the univariate analysis did, due to the correlation between age and years in practice. Younger age, which usually correlates with less professional experience, increases work-related stress which may account for the observed EE and DP.

Burn clinicians not only identified as having a higher risk of burnout but also exhibited clinically significantly lower levels of mental QoL and clinically significantly higher levels of physical QoL. Furthermore, $43.6 \%$ of clinicians received $<6$ hours of sleep per night and therefore could be classified as sleep deprived. ${ }^{31-33}$ This finding can be explained by the high prevalence of depression identified in burn care clinicians experiencing burnout alongside their young age, as younger clinicians tend to have higher physical QoL compared to older clinicians, with younger clinicians being more prone to developing burnout and compassion fatigue symptoms. The lack of compensation and coping mechanisms in younger, more inexperienced, clinicians leads to increased vulnerability to job demands compared to older, more experienced, clinicians who are more resilient. ${ }^{34}$

Our study found that burnout may impact career satisfaction and PA, factors that may possibly lead to cost of caring among burn care professionals. These results are supported by previous studies in similar clinical care settings demonstrating the need to further reduce the potential for burnout. ${ }^{11,35}$ 
The possible relationship between clinicians' burnout and cost of caring has important implications for multilevel efforts to prevent and treat burnout, to minimize errors, and to improve standards of care. ${ }^{33}$ These findings demonstrate the importance of promoting well-being and a supportive workplace environment among medical clinicians in order to seek help when needed, while also recognizing burnout and its impact personally and professionally. Identifying burnout and its implications is often difficult because of its varied manifestations in addition to the clinicians' tendency to suppress and deny any suggestion of a problem. Clinicians seem more reluctant to seek help than do other professionals, ${ }^{36,37}$ mostly because of concerns about confidentiality. ${ }^{38}$ Shanafelt et $\mathrm{a}^{39}$ suggest that this attitude is widespread within the surgical specialties. Nevertheless, professional support, coupled with workplace interventions including reduced working hours, has been demonstrated to reduce physician burnout and attrition. ${ }^{40}$

Identification of burnout is essential not only for healthcare professionals' QoL, but also because well-being of patients may be at stake. Importantly, once identified and treated, clinicians are able to return to a meaningful career and family and personal life. ${ }^{41}$ Such efforts may lend themselves to improved occupational fulfillment and a sense of well-being with a reduction in the prospect of clinicians encountering stress and burnout. ${ }^{42}$ Importantly, burnout remains a cross-cultural issue for health professionals. ${ }^{1,2}$

Additional risk factors for burnout, such as young age, the lack of family supportive network (such as children and spouse), and the effects of burnout and compassion fatigue on QoL and career satisfaction, demonstrate the need for better screening tools for burnout. In addition, these results suggest a need for better suited support systems and networks as an integral part of training and residency programs, with aims to provide young, less experienced, clinicians with the support needed to prevent the development of burnout symptoms and compassion fatigue, especially in burn centers. As demonstrated in our study, a supportive network at home might be crucial for handling the challenges faced by clinicians in their daily routine. Frequent psychological interviews and assessments can be used as both a screening tool and a tool to reduce burnout symptoms. Since burnout rates are lower in older, more experienced, clinicians, mentoring programs and small group meetings dedicated to sharing stories and handling stress may provide an additional support network to prevent possible symptoms of burnout. Spickard et $\mathrm{al}^{43}$ state that clinicians should engender resilience and emotional intelligence early in their training to ensure longevity of their career. Furthermore, instituting self-care practices that accommodate the uncertainties of a changing health care environment may affect the retention and recruitment of health practitioners. . $^{23,30,44}$

\section{Strengths and limitations}

The analysis performed in this study used multiple logistic and linear regressions in addition to the univariable analysis in order to isolate the relationship between the exposure variable and the outcome variable from the effects of confounding. While the response rate was 95\%, incomplete questionnaires were noted, further reducing the pool of available data. This study was conducted across three settings including Burns, Plastic and Reconstructive surgery and ICU in a large tertiary teaching hospital. However, the results are limited by the relatively small subgroup sample size, thus reducing the statistical power of the study, in particular the multivariate analysis, and the study was conducted in only one hospital, limiting the generalizability to other settings and organizations. Furthermore, the clinicians surveyed only treated adults and hence the results of this study may underrepresent burnout for pediatric settings. Subsequently, the experiences of managing pediatric trauma may have a significant impact on burnout and compassion fatigue. Therefore, a larger sample size incorporating a multisite approach would offer a broader scope and have demographic variables. This study utilized a cross-sectional design and therefore limits the capacity to determine the prevalence of burnout and compassion fatigue longitudinally as perceptions would change over time because of the individual and his or her workplace environment. Despite the limitations identified, this study provides knowledge on vicarious trauma, burnout, and compassion fatigue encountered within the burns setting.

\section{Conclusion}

The social environment of a workplace and the organizational structure are particularly relevant contributing factors to burnout and compassion fatigue. Subsequently, the effects of burnout and compassion fatigue on QoL and career satisfaction may lead to deterioration of the quality of care and worsening patient outcomes. Therefore, understanding the unique needs of this demographic group provides direction to facilitate with staff retention and recruitment within the domain of burns and trauma. Our study highlights the necessity for burns and trauma clinicians to develop resilient behaviors to endure the emotional trauma of treating those with severe burns and traumatic injuries. Clinicians need to be mindful of compassion fatigue and burnout among their colleagues, 
and the development of therapeutic alliances among peers on the basis of respect, empathy, and compassion for others can support a positive workforce environment and relations. Providing assistance and effective interventions to protect clinicians from the effects of compassion fatigue and burnout is of prime importance. Psychosocial support could be implemented through means of debriefing sessions that are hosted by appropriate clinicians (social workers, psychologists, or psychiatrists). Furthermore, embedding a supportive workplace culture is a key factor in reducing the impact of burnout among colleagues. This may assist with future recruitment and retention of trauma clinicians. Subsequently, efforts to better understand, prevent, and treat the symptoms of burnout and compassion fatigue among burn clinicians are essential for both their QoL and patients' quality of care.

\section{Disclosure}

The authors report no conflicts of interest in this work.

\section{References}

1. Squires A, Finlayson C, Gerchow L, et al. Methodological considerations when translating "burnout". Burn Res. 2014;1(2):59-68.

2. Galiana L, Arena F, Oliver A, Sansó N, Benito E. Compassion satisfaction, compassion fatigue, and burnout in Spain and Brazil: ProQOL validation and cross-cultural diagnosis. J Pain Symptom Manage. 2017;53(3):598-604.

3. Boscarino JA, Figley CR, Adams RE. Compassion fatigue following the September 11 terrorist attacks: a study of secondary trauma among New York City Social Workers. Int J Emerg Ment Health. 2004;6(2): 57-66.

4. Hinderer KA, VonRueden KT, Friedmann E, et al. Burnout, compassion fatigue, compassion satisfaction, and secondary traumatic stress in trauma nurses. J Trauma Nurs. 2014;21(4):160-169.

5. Devilly GJ, Wright R, Varker T. Vicarious trauma, secondary traumatic stress or simply burnout? Effect of trauma therapy on mental health professionals. Aust N Z J Psychiatry. 2009;43(4):373-385.

6. Maslach C, Jackson SE, Leiter MP. Maslach burnout inventory. Evaluating Stress: A Book Res. 1997;3:191-218.

7. Ohaeri J. The burden of caregiving in families with a mental illness: a review of 2002. Curr Opin Psychiatry. 2003;16(4):457-465.

8. Bellolio MF, Cabrera D, Sadosty AT, et al. Compassion fatigue is similar in emergency medicine residents compared to other medical and surgical specialties. West J Emerg Med. 2014;15(6):629-635

9. Weintraub AS, Geithner EM, Stroustrup A, Waldman ED. Compassion fatigue, burnout and compassion satisfaction in neonatologists in the US. J Perinatol. 2016;36(11):1021-1026.

10. Newman E, Risch E, Kassam-Adams N. Ethical issues in trauma-related research: a review. J Empir Res Hum Res Ethics. 2006;1(3):29-46.

11. Shanafelt TD, Balch CM, Bechamps GJ, et al. Burnout and career satisfaction among American surgeons. Ann Surg. 2009;250(3): 463-471.

12. Maslach C, Jackson SE, Leiter MP. Maslach burnout inventory. In: P. ZC, J. WR, editors. Evaluating Stress: A Book of Resources. 3rd ed. NY, USA: Scarecrow Press; 1997:191-218.

13. Schaufeli WB. Burnout. Chichester, NY: Wiley; 1999.

14. Tamburrino MB, Lynch DJ, Nagel RW, Smith MK. Primary care evaluation of mental disorders (PRIME-MD) screening for minor Depressive disorder in primary care. Prim Care Companion J Clin Psychiatry. 2009; 11(6):339-343.
15. Roberts B, Browne J, Ocaka KF, Oyok T, Sondorp E. The reliability and validity of the SF-8 with a conflict-affected population in northern Uganda. Health Qual Life Outcomes. 2008;6:108-108.

16. West CP, Huschka MM, Novotny PJ, et al. Association of perceived medical errors with resident distress and empathy: a prospective longitudinal study. JAMA. 2006;296(9):1071-1078.

17. Kuerer HM, Eberlein TJ, Pollock RE, et al. Career satisfaction, practice patterns and burnout among surgical oncologists: report on the quality of life of members of the Society of Surgical Oncology. Ann Surg Oncol. 2007;14(11):3043-3053.

18. Stamm B. The concise ProQOL manual. 2nd ed. Pocatello,: ID: ProQOL.org; 2010.

19. Conrad D, Kellar-Guenther Y. Compassion fatigue, burnout, and compassion satisfaction among Colorado child protection workers. Child Abuse Negl. 2006;30(10):1071-1080.

20. Balch CM, Shanafelt TD, Sloan JA, Satele DV, Freischlag JA. Distress and career satisfaction among 14 surgical specialties, comparing academic and private practice settings. Ann Surg. 2011;254(4):558-568.

21. Steenkamp WC, van der Merwe AE. The psychosocial functioning of nurses in a burn unit. Burns. 1998;24(3):253-258.

22. Rafii F, Oskouie F, Nikravesh M. Factors involved in nurses' responses to burnout: a grounded theory study. BMC Nurs. 2004;3(1):1-10.

23. Kornhaber RA, Wilson A. Building resilience in burns nurses: a descriptive phenomenological inquiry. J Burn Care Res. 2011;32(4): $481-488$.

24. Kornhaber RA, Wilson A. Enduring feelings of powerlessness as a burns nurse: a descriptive phenomenological inquiry. Contemp Nurse. 2011;39(2):172-179.

25. Froutan R, Khankeh HR, Fallahi M, Ahmadi F, Norouzi K. Pre-hospital burn mission as a unique experience: a qualitative study. Burns. 2014; 40(8):1805-1812.

26. Sahraian A, Fazelzadeh A, Mehdizadeh AR, Toobaee SH. Burnout in hospital nurses: a comparison of internal, surgery, psychiatry and burns wards. Int Nurs Rev. 2008;55(1):62-67.

27. Lewis KF, Poppe S, Twomey J, Peltier G. Survey of perceived stressors and coping strategies among burn unit nurses. Burns. 1990;16(2): 109-112.

28. Pauker SL. A new use for videotape in liaison psychiatry: a case from the burn unit. Gen Hosp Psychiatry. 1986;8(1):11-17.

29. Camhi C, Cohn N. Working with patients who have big burns: exploring the perspectives of senior medical staff of different professional groups. J Burn Care Res. 2007;28(1):187-194.

30. van Mol M, Kompanje E, Benoit D, Bakker J, Nijkamp M, Seedat S. The prevalence of compassion fatigue and burnout among healthcare professionals in intensive care units: a systematic review. PLoS One. 2015;10(8):e0136955.

31. Lockley SW, Barger LK, Ayas NT, Rothschild JM, Czeisler CA, Landrigan CP. Effects of health care provider work hours and sleep deprivation on safety and performance. Jt Comm J Qual Patient Saf. 2007; 33(11 Suppl):7-18.

32. Lockley SW, Cronin JW, Evans EE, et al. Effect of reducing interns' weekly work hours on sleep and attentional failures. $N$ Engl J Med. 2004;351(18):1829-1837.

33. Qureshi HA, Rawlani R, Mioton LM, Dumanian GA, Kim JY, Rawlani V. Burnout phenomenon in U.S. plastic surgeons: risk factors and impact on quality of life. Plast Reconstr Surg. 2015;135(2):619-626.

34. Ramos R, Jenny G, Bauer G. Age-related effects of job characteristics on burnout and work engagement. Occup Med (Lond). 2016;66(3): 230-237.

35. Dyrbye LN, Varkey P, Boone SL, Satele DV, Sloan JA, Shanafelt TD. Physician satisfaction and burnout at different career stages. Mayo Clin Proc. 2013;88(12):1358-1367.

36. Brooks SK, Gerada C, Chalder T. Review of literature on the mental health of doctors: are specialist services needed? J Ment Health. 2011; 20(2):146-156.

37. Rosvold EO, Bjertness E. Illness behaviour among Norwegian physicians. Scand J Public Health. 2002;30(2):125-132. 
38. Davidson SK, Schattner PL. Doctors' health-seeking behaviour: a questionnaire survey. Med J Aust. 2003;179(6):302-305.

39. Shanafelt TD, Balch CM, Dyrbye L, et al. Special report: suicidal ideation among American surgeons. Arch Surg. 2011;146(1):54-62.

40. Ro KE, Gude T, Tyssen R, Aasland OG. Counselling for burnout in Norwegian doctors: one year cohort study. BMJ. 2008;337:1-8.

41. Boisaubin EV, Levine RE. Identifying and assisting the impaired physician. Am J Med Sci. 2001;322(1):31-36.
42. Wallace JE, Lemaire JB, Ghali WA. Physician wellness: a missing quality indicator. Lancet. 2009;374(9702):1714-1721.

43. Spickard A Jr, Gabbe SG, Christensen JF. Mid-career burnout in generalist and specialist physicians. JAMA. 2002;288(12):1447-1450.

44. Reed CE, Vaporciyan AA, Erikson C, et al. Factors dominating choice of surgical specialty. J Am Coll Surg. 2010;210(3):319-324.

\section{Publish your work in this journal}

Neuropsychiatric Disease and Treatment is an international, peerreviewed journal of clinical therapeutics and pharmacology focusing on concise rapid reporting of clinical or pre-clinical studies on a range of neuropsychiatric and neurological disorders. This journal is indexed on PubMed Central, the 'PsycINFO' database and CAS, and is the official journal of The International Neuropsychiatric Association (INA). The manuscript management system is completely online and includes a very quick and fair peer-review system, which is all easy to use. Visit http://www.dovepress.com/testimonials.php to read real quotes from published authors.

\footnotetext{
Submit your manuscript here: http://www.dovepress.com/neuropsychiatric-disease-and-treatment-journal
} 